\title{
Acute Glycemic Changes in Brain and Subcutaneous Tissue Measured by Continuous Glucose Monitoring System in Hereditary Hypertriglyceridemic Rat
}

\author{
M. ŽOUREK ${ }^{1}$, P. KYSELOVÁ ${ }^{1}$, D. ČECHUROVÁ ${ }^{1}$, Z. RUŠAVÝ $^{1}$ \\ ${ }^{1}$ First Department of Medicine, Charles University in Prague, Medical School and Teaching \\ Hospital in Pilsen, Pilsen, Czech Republic
}

Received February 20, 2017

Accepted June 19, 2017

On-line November 10, 2017

\section{Summary}

Parallel glucose measurements in blood and other different tissues give us knowledge about dynamics of glycemia changes, which depend on vascularization, distribution space and local utilization by tissues. Such information is important for the understanding of glucose homeostasis and regulation. The aim of our study was to determine the time-lag between blood, brain, and adipose tissue during rapid glucose changes in a male hHTG rat $(n=15)$. The CGMS sensor Guardian RT (Minimed/Medtronic, USA) was inserted into the brain and into the abdominal subcutaneous tissue. Fixed insulin and variable rate of glucose infusion was used to maintain euglycemia during sensor calibration period. At $0 \mathrm{~min}, 0.5 \mathrm{~g} / \mathrm{kg}$ of bolus of glucose was administered, and at $50 \mathrm{~min}, 5 \mathrm{IU} / \mathrm{kg}$ of bolus of insulin was administered. Further glucose and insulin infusion was stopped at this time. The experiment was finished at $130 \mathrm{~min}$ and animals were euthanized. The time-shift between glycemia changes in blood, brain, and subcutaneous tissue was calculated by identification of the ideal correlation function. Moreover, the time to achieve $90 \%$ of the maximum glucose excursion after intervention (T90) was measured to compare our data with the literature. The time-lag blood vs. brain and blood vs. subcutaneous tissue was $10(10 ; 15) \min$ and $15(15 ; 25) \mathrm{min}$, respectively. The difference was statistically significant $(P=0.01)$. T90 after glucose bolus in brain and subcutaneous tissue was $10 \mathrm{~min}(8.75 ; 15)$ and $15 \mathrm{~min}(13.75 ; 21.25)$, respectively. T90 after insulin bolus in brain and subcutaneous tissue was $10 \mathrm{~min}(10 ; 15)$ and $20 \mathrm{~min}(20 ; 27.5)$, respectively. To the contrary, with literature, our results showed earlier glucose level changes in brain in comparison with subcutaneous tissue after glucose and insulin boluses. Our results suggest that glucose dynamics is different within monitored tissues under rapid
\end{abstract}

changing glucose level and we can expect similar behavior in humans. Improved knowledge about glucose distribution and dynamics is important for avoiding hypoglycemia.

\section{Key words}

Glucose • Brain • Continuous glucose measurement system • Rat

\section{Corresponding author}

M. Zourek, First Department of Medicine, Charles University in Prague, Medical School and Teaching Hospital in Pilsen, Alej Svobody 80, 30000 Pilsen, Czech Republic. E-mail: zourek@fnplzen.cz

\section{Introduction}

Diabetes is a rapidly increasing disease affecting large populations worldwide. Several novel approaches in treatment and monitoring have been developed in the last decade. It has been proven, that better glucose control improves morbidity and mortality of diabetics (ACCORD, DCCT-EDDIC, UKPDS). The continual glucose monitoring system (CGMS) is a technology changing the current concept of glycemia control in diabetic patients. In contrast to glucometers that only provide single glucose measurements, CGMS is able to measure the glycemia level in real time. CGMS is based on a sensor introduced into subcutaneous tissue, and glucose is measured in an interstitial fluid (Hirsch et al. 2008). Most of the available continual glucose monitoring systems are based on sensors with glucose oxidase enzyme.

CGMS technology provides an opportunity to 
measure glycemia not only in subcutaneous tissue, but also in tissues responsible for glucose sensing, like B-cells, adipose tissue, and brain (Penicaud et al. 2002).

Parallel glucose measurements in blood and subcutaneous tissue provide information on the dynamics of glycemia changes, which depend on vascularization, distribution space, and local utilization by tissues. Such information is important for the understanding of glucose homeostasis and regulation.

A previous study on dogs, where CGMS sensors were used for glycemia measurements in adipose tissue compared with blood, showed a time-lag in glycemia changes around $5 \mathrm{~min}$ during a hyperglycemic clamp (Rebrin et al. 1999). In a contrary study on pigs, where continual glucose measurements were performed by microdialysis in brain, adipose tissue and muscle did not show any changes in glycemia dynamics after bolus of glucose between those tissues (Nielsen et al. 2005). However, microdialysis is a technique that is not so suitable for measurements of rapid glycemia changes.

The aim of our study was to determine the time-lag between blood, brain, and adipose tissue during rapid glucose changes in a rat model of metabolic syndrome.

Prague hereditary hypertriglyceridemic rats (hHTG) were originally derived from a colony of Wistar rats (Vrána and Kazdová 1990). The hHTG rat is a strain expressing hereditary hypertriglyceridemia and associates hyperinsulinemia and hypertension (Vrána and Kazdová 1990). This strain of rat is a relevant model of metabolic syndrome and it is available for assessment of the lipoprotein metabolism and insulin resistance (Ueno et al. 2004, Žourek et al. 2008).

\section{Material and Methods}

Male $\mathrm{hHTG}$ rats $(\mathrm{n}=15)$ were provided by doctor Kazdová (IKEM, Prague). The rats were maintained at a constant temperature $\left(23 \pm 1^{\circ} \mathrm{C}\right)$, with a fixed $12 \mathrm{~h}$ artificial light period. They were housed in stainless steel cages (4 rats per cage) and allowed free access to water and standard chow. At the beginning of the experiment, the rats were aged 3 months. All procedures and experimental protocols were approved by the local animal Ethics Committee of the Faculty of Medicine Charles University in Pilsen.

Surgical preparations were described in our previous study (Žourek et al. 2008). After intraperitoneal anesthesia (ketamine $100 \mathrm{mg} / \mathrm{kg}$ i.p. + xylazine $16 \mathrm{mg} / \mathrm{kg}$ i.p. + Urethane $1.2 \mathrm{~g} / \mathrm{kg}$ i.p.), a small incision was made $0.5 \mathrm{~cm}$ from the cervical midline and at the level of the forelegs, and the internal jugular vein was exposed. After superior ligation, the vessel was catheterized with silastic tubing, and the carotid artery was catheterized on the same side. All skin incisions were closed with 3-0 thread and the catheters were filled with normal saline. After both catheters were prepared, an incision was made over the top of the skull and the brain was exposed through $2 \mathrm{~mm}$-diameter burr holes over the cingulate cortex on the right side of the midline. The CGMS sensor Guardian RT (Minimed/Medtronic, USA) was inserted into the brain by micromanipulators. The subcutaneous sensor (Minimed/Medtronic Guardian RT) was inserted into the abdominal subcutaneous tissue after skin pre-puncture with a 16-gauge needle.

After insertion, both sensors were attached to the transmitter. No bleeding was observed with any of the devices upon insertion. The rats remained anesthetized throughout the experiment.

At the beginning of the experiment $(-120 \mathrm{~min})$, basal glycemia was measured (HemoCue, Sweden) and calibration of the sensors was started. Thereafter, insulin (Actrapid, Novo Nordisk, Denmark) was started at an infusion rate of $50 \mathrm{mU} / \mathrm{kg} / \mathrm{min}$ and $20 \%$ glucose was started at a variable rate of infusion. Blood glycemia was measured every $5 \mathrm{~min}$ with manual correction of the glucose infusion rate to maintain a glycemia level of $6 \mathrm{mmol} / \mathrm{l}$. At $-10 \mathrm{~min}$, the calibration procedure was finished and the actual glycemia was recorded with the sensors. At $0 \mathrm{~min}, 0.5 \mathrm{~g} / \mathrm{kg}$ of bolus of glucose was administered, and at $50 \mathrm{~min}, 5 \mathrm{IU} / \mathrm{kg}$ of bolus of insulin was administered. Further glucose and insulin infusion was stopped at this time. The experiment was finished at 130 min and animals were euthanized (Fig. 1).

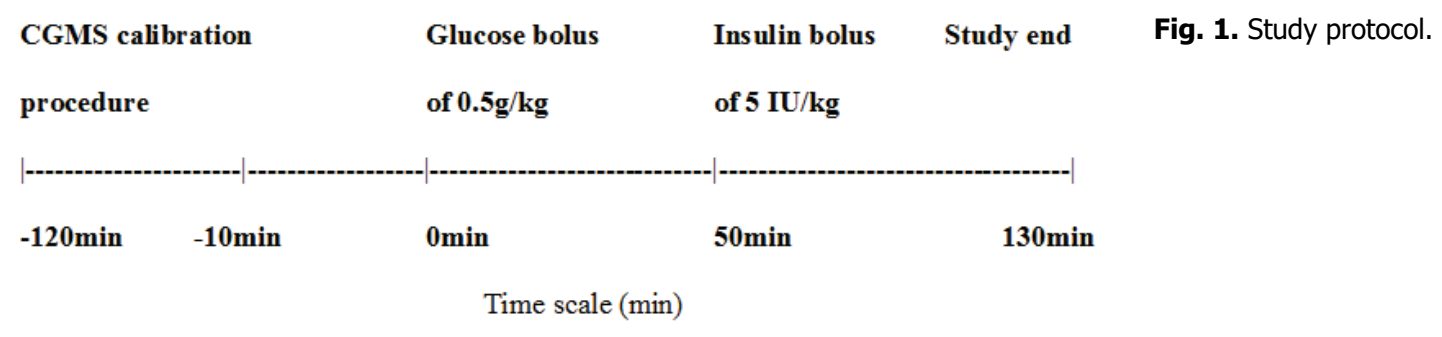




\section{Statistical analysis}

Analysis of variance was used to compare multiple group means. When the data was not normally distributed, the Wilcoxon test was performed to compare group means. The time-shift between glycemia changes in blood, brain, and subcutaneous tissue was calculated by identification of the ideal correlation function. Moreover, the time to achieve $90 \%$ of the maximum glucose excursion after intervention (T90) was measured to compare our data with the literature. $P<0.05$ was considered statistically significant. All data is expressed as median and interquartile range.

\section{Results}

Time-paired glycemia measurements obtained from animals were further analyzed. The concentrations of glucose in blood, brain, and subcutaneous tissue are summarized in Figure 2. After an intravenous glucose bolus of $0.5 \mathrm{~g} / \mathrm{kg}$, glycemia rose rapidly to $14 \mathrm{mmol} / \mathrm{l}$ in 5 min. In contrast, glucose content in the brain and subcutaneous tissue was increased in a slower manner, reaching a maximum after $50 \mathrm{~min}$ and $60 \mathrm{~min}$, respectively. After an intravenous insulin bolus of $5 \mathrm{IU} / \mathrm{kg}$, the blood glucose concentration was lowered to a minimum of $4.5 \mathrm{mmol} / \mathrm{l}$. Brain and subcutaneous tissue glucose content decreased slowly to a minimum of $4.2 \mathrm{mmol} / \mathrm{l}$ and $5.5 \mathrm{mmol} / \mathrm{l}$, respectively.

Correlation coefficients were calculated for time-shifts between blood, brain a subcutaneous tissue. The time-lag blood vs. brain and blood vs. subcutaneous tissue was $10(10 ; 15) \mathrm{min}, \mathrm{r}=0.90(0.88 ; 0.92)$ and $15(15 ; 25) \min , \mathrm{r}=0.89(0.82 ; 0.93)$, respectively. The difference was statistically significant $(P=0.01)$.

The time from the glucose peak in arterial blood to T90 in subcutaneous tissue and brain is shown in Table 1.

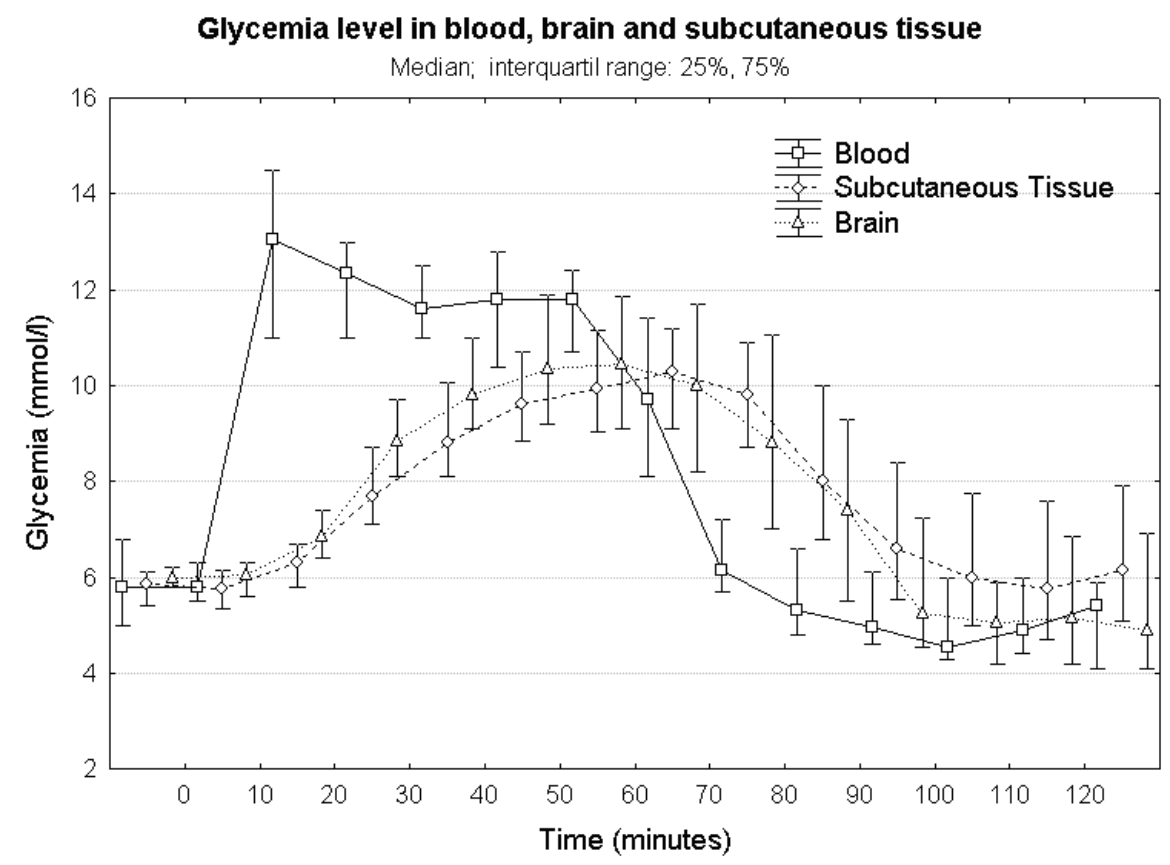

Fig. 2. Glycemia was measured by HemoCue in blood and recorded by CGMS in brain and subcutaneous tissue. A glucose bolus of $0.5 \mathrm{~g} / \mathrm{kg}$ was administered at $0 \mathrm{~min}$ and an insulin bolus of $5 \mathrm{IU} / \mathrm{kg}$ was administered at $50 \mathrm{~min}$.

Table 1. Glucose arterial peak to T90.

\begin{tabular}{lccc}
\hline & Brain (min) & Subcutaneous tissue (min) & $P$ \\
\hline Glucose bolus & $10(8.75 ; 15)$ & $15(13.75 ; 21.25)$ & 0.020 \\
Insulin bolus & $10(10 ; 15)$ & $20(20 ; 27.5)$ & 0.003 \\
\hline
\end{tabular}

Data expressed as median (interquartile range). 


\section{Discussion}

Minimally invasive glucose sensors are widely used for real-time glucose measurements from subcutaneous adipose tissue. These sensors are able to measure glucose in different tissues with enough interstitial fluid to keep the electrode moistened. In our work, we used the Guardian RT sensor for parallel glucose measurements in brain and adipose tissue for the first time. Guardian RT sensors convert current to frequency, which is counted over a $1 \mathrm{~min}$ interval, and is processed by a special moving average filter, and decimated to a $5 \mathrm{~min}$ sample interval. This signal processing leads to an interstitial fluid to plasma glucose delay of 8.25 min (Keenan et al. 2009).

Previous works used microelectrodes or a microdialyzation technique for glucose measurement in different tissues.

A study on rats focused on glucose changes in the brain under normal and hypoxic conditions during normoglycemia, hypoglycemia, and hyperglycemia. Authors showed that microelectrode technology is suitable for continuous glucose monitoring and found that glucose content in the brain is rapidly decreasing under hypoxia. Nevertheless, the experiment was not designed for glucose monitoring in the brain during rapidly changing systemic glycemia (Silver et al. 1994).

Microdialysis technology for glucose measurements in cerebral cortex, muscle, and adipose tissue was used in another study on pigs with a similar design to ours. The authors used glucose boluses of 10,20 , and $50 \mathrm{~g}$ and insulin boluses of 10, 30, and $50 \mathrm{IU}$. The time-lag was calculated as the time from the glucose arterial peak to T90, and no significant delays were found. Only the amplitudes of glucose excursions were different in monitored tissues. The average time from the glucose arterial peak to the T90 was around $20 \mathrm{~min}$. The authors concluded that subcutaneous tissue is suitable for glucose measurements because of the similar time-lag in other tissues (Nielsen et al. 2005). However, microdialysis technology has some limitations in measurements of rapidly changing variables, because of the slow perfusion rate of dialysate.
A human study on type 1 diabetics and healthy volunteers focused on the relationship between plasma and brain glucose levels during euglycemia. Hypoglycemia showed a linear Michaelis-Menten relationship even for the low plasma glucose values. Brain glucose content in this study was measured by

${ }^{13} \mathrm{C}$ magnetic resonance spectroscopy during the steady state of each clamp and was not suitable to show any data of glucose dynamics under rapidly changing conditions (Van de Ven et al. 2012).

To the contrary, our results showed earlier glucose level changes in brain in comparison to subcutaneous tissue after glucose and insulin boluses. We used a mathematic method based on the identification of the ideal correlation function for time-shift calculations between different tissues. This method has been proven for such calculations. However, we observed similar results even after the calculation of the time from the glucose arterial peak to T90 (Table 1).

The limitation of our study was that we were not able to measure glucose in an exact brain structure because of the sensor length and diameter. Therefore, we cannot conclude that the observed glucose dynamics are the same for different central nervous system structures. Animal data also cannot be easily extrapolated to humans. Our results show that glucose dynamics are different within monitored tissues under rapidly changing glucose levels, and we can expect similar behavior in humans. Improved knowledge about glucose distribution and dynamics is important for avoiding hypoglycemia.

\section{Conclusions}

Our data showed that glucose in the brain follows blood excursions during acute glycemic changes more closely than subcutaneous tissue.

\section{Conflict of Interest}

There is no conflict of interest.

\section{Acknowledgements}

This study was supported by the Charles University Research Fund (project number Q39).

\section{References}

HIRSCH IB, ARMSTRONG D, BERGENSTAL RM, BUCKINGHAM B, CHILDS BP, CLARKE WL, PETERS A, WOLPERT H: Clinical application of emerging sensor technologies in diabetes management: consensus guidelines for continuous glucose monitoring (CGM). Diabetes Technol Ther 10: 232-244; quiz 245-246, 2008. 
KEENAN DB, MASTROTOTARO JJ, VOSKANYAN G, STEIL GM: Delays in minimally invasive continuous glucose monitoring devices: a review of current technology. J Diabetes Sci Technol 3: 1207-1214, 2009.

NIELSEN JK, DJURHUUS CB, GRAVHOLT CH, CARUS AC, GRANILD-JENSEN J, ORSKOV H, CHRISTIANSEN JS: Continuous glucose monitoring in interstitial subcutaneous adipose tissue and skeletal muscle reflects excursions in cerebral cortex. Diabetes 54: 1635-1639, 2005.

PENICAUD L, LELOUP C, LORSIGNOL A, ALQUIER T, GUILLOD E: Brain glucose sensing mechanism and glucose homeostasis. Curr Opin Clin Nutr Metab Care 5: 539-543, 2002.

REBRIN K, STEIL GM, VAN ANTWERP WP, MASTROTOTARO JJ: Subcutaneous glucose predicts plasma glucose independent of insulin: implications for continuous monitoring. Am J Physiol 277: E564-E571, 1999.

SILVER IA, ERECINSKA M: Extracellular glucose concentration in mammalian brain: continuous monitoring of changes during increased neuronal activity and upon limitation in oxygen supply in normo-, hypo-, and hyperglycemic animals. J Neurosci 14: 5068-5076, 1994.

UENO T, TREMBLAY J, KUNES J, ZICHA J, DOBESOVA Z, PAUSOVA Z, DENG AY, SUN YL, JACOB HJ, HAMET P: Rat model of familial combined hyperlipidemia as a result of comparative mapping. Physiol Genomics 17: 38-47, 2004.

VAN DE VEN KC, VAN DER GRAAF M, TACK CJ, HEERSCHAP A, DE GALAN BE: Steady-state brain glucose concentrations during hypoglycemia in healthy humans and patients with type 1 diabetes. Diabetes 61: 1974-1977, 2012.

VRÁNA A, KAZDOVÁ L: The hereditary hypertriglyceridemic nonobese rat: an experimental model of human hypertriglyceridemia. Transplant Proc 22: 2579, 1990.

ŽOUREK M, KYSELOVÁ P, MUDRA J, KRČMA M, JANKOVEC Z, LACIGOVÁ S, VÍŠEK J, RUŠAVÝ Z: The relationship between glycemia, insulin and oxidative stress in hereditary hypertriglyceridemic rat. Physiol Res 57: 531-538, 2008. 